\title{
Sea level rise - How much and how fast will sea level rise over the coming centuries?
}

Sea level is a sensitive indicator of climate change and responds to global warming both directly and seawater expands, and also as mountain glaciers and ice sheets melt in response to increasing temperature. Tide gauge measurements available since the late $19^{\text {th }}$ century indicate that the global mean sea level has risen by an average of $1.7-1.8$ $\mathrm{mm}$ year ${ }^{-1}$ during the $20^{\text {th }}$ century (Church and White 2011), marking the end of the relative stability of the past three millennia. Satellite data available since 1993 point to a higher mean rate of sealevel rise of $3.2 \pm 0.4 \mathrm{~mm}$ year ${ }^{1}$ during the past two decades (Cazenave and Remy 2011)

Ocean temperature data suggest that ocean thermal expansion has significantly $20^{0^{2}}$ century of the sea-level rise observed since 1993 (Cazenave and Remy 2011; Church et al. 2011a). Numerous observations have reported a worldwide retreat of glaciers during recent decades, with a significant acceleration of this retreat during the 1990s: this also contributes to about 30\% of the sea-level rise. Change in land water storage due to natural climate variability contributes negligibly to sea level rise. Hu-

man activities (mostly underground water mining and dam building along rivers have had large effects on sea level during ly canceled each other out (Church et al.

Little was known before the 1990 n the mass balance of the ice sheets because of inadequate and incomplete observations. But remote sensing techniques available since then suggest that the Greenland and West Antarctic ice sheets are losing mass at an accelerated rete, mostly from rapid outlet glacier flow and further iceberg discharge into the surrounding ocean (Steffen et al. 2010; Pfeffer 2011). For the period 1993-2003, less than $15 \%$ of the rate of global sea-level rise was due to the ice sheets. But their contribution has increased to $~ 70 \%$ since 2003 2004. Although not constant through tme, mass loss from the ice sheets ex plains $\sim 25 \%$ of the rate of sea-level rise since the early 1990s (Cazenave and Rem

There is litle doubt that global warming will continue and even increase duing the future decades as greenhouse gas pissions, the main contributor to anthroogenic global warming, are likely to keep sessment report of the Interge fourth as-

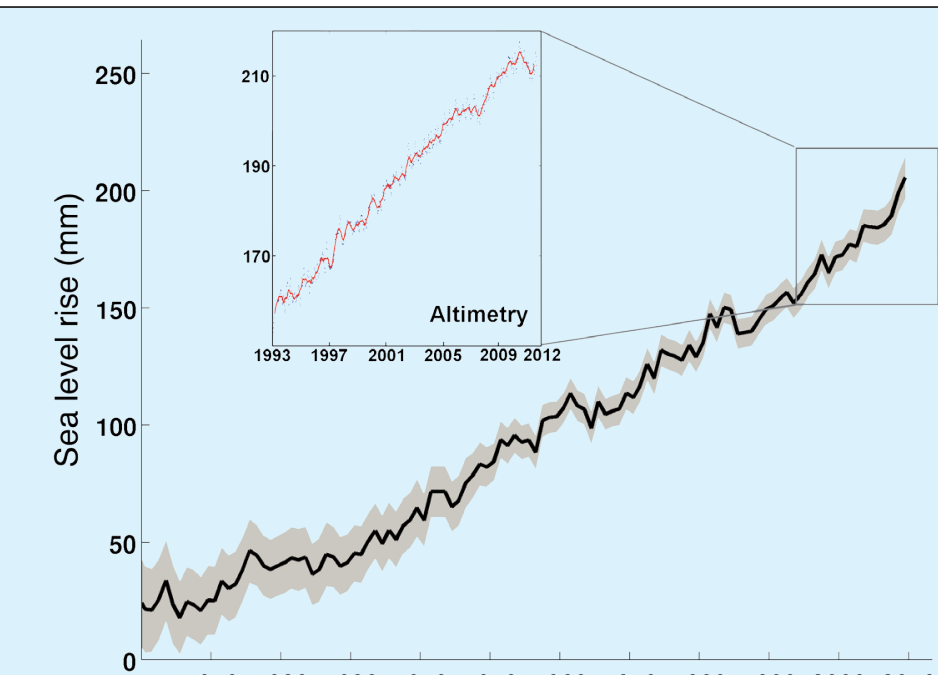

19101920193019401950196019701980199020002010

Year AD

Figure 1: Twentieth century sea level curve (in black and associated uncertainty in light gray) based on tide gauge
data and additional information (data from Church and White 2011). Box:altimetry-based sea level curve between

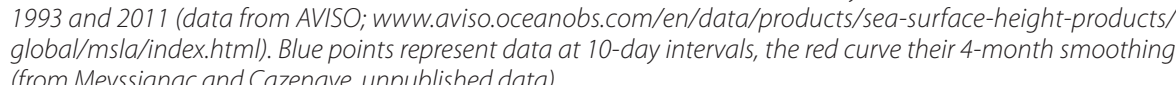

Panel on Climate Change (IPCC 2007) indicate that sea level in the year 2100 should be higher than today's value by $40 \mathrm{~cm}$ (within a range of $+15 \mathrm{~cm}$ due to model results dispersion and uncertainty on emis. sions). More recently it has been suggested that this value could be a lower bound. This is because the climate models at the time accounted for ocean warming and glacial melting (plus a surface mass balance component for the ice sheets) (IPCC 2007), but not for the recently observed dynamical processes that became quite active during the last decade (Steffen et al.

Thus, mass loss from ice sheets could eventually represent a much larger contriously expected (Pfeffer 2011). Yet, despite much recent progress in process understanding and modeling, the ice sheet contribution to $21^{\text {st }}$ century sea-level rise remains highly uncertain. Values around $30-50 \mathrm{~cm}$ by 2100 cannot be ruled out for the total land ice (glaciers plus ice sheets) contribution. If we add the ocean-warming component (in the range $20-30 \mathrm{~cm}$; IPCC 2007), global mean sea level at the end of this century could eventually exceed present-day elevation by $50-80 \mathrm{~cm}$ (e.g. Church et al. 2011b).

Providing realistic sea-level projections remains a high priority in the climate modeling community given their importance to developing realistic coastal management and adaptation plans. But sustained and systematic monitoring of sea level and ofher climate parameters causing sea-level rise - for example, ocean heat The better we understand present-day The better we understand present-day we will be able to project changes in future sea level.

Selected references Full reference listoninin under

Cazenave A and Remy F (2011) Iteredisisipinary Reviews: Climate
Change 2(5): $647-662$ ) Church JA And White N (2011) Surversin Geophysic 32(4-5): 585-602

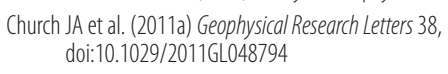
Preffer WT (2011) Oceanogoraphy 242(2):94-11

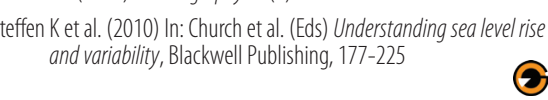

Mark Siddal' And David Polard 2 2Earth and Environmental Systems Institute, Pennsylvania State University, University Park, USA
The time scales of major West Antarctic Ice Sheet (WAIS) growth and retreat are centuries to millennia. Instrumental records cades long and can therefore only offer cent observed breakup of some Peninsula ice shelves, and accelerated flow and thinning of their upstream glaciers and Pine Island-Thwaites glaciers (eg Shepherd et al. et al. 2010), may be harbingers of future retreat, but by themselves shed little light on potential progression into a full collapse of central WAIS. If anything, contemporary observations indicate ever more pressingly derstand the collapse of the WAIS. Sub-ice shelf warming of part of the WAIS (Jenkins nomena bringing warm water masses onto the shelf next to the WAIS that may well turn out to be analogous to past collapse events once we understand more fully the processnot just the ice sheet itself, but the oceanogshelf systems. Oceanic modeling of these systems is challenging, and studies of past and future changes are in early stages of development (e.g. Holland et al. 2008; Olbers and Hellmer 2010; Dinniman et al. 2011). This is where studies such as ANDRILL (Naish et al. 2009) that span the relevant time periods truly come into their own. Such studies have provided substantial evidence from different climate states implying that drastic collapses of marine-based WAIS occurred single snapshot of a moving target. The re2003; Pritchard and Vaughan 2007: Jenkins that paleo data are uniquely placed to unet al. 2010) indicates oceanographic phees behind them. It is critical to understand, raphy of the Antarctic shelves and sub-ice during the warmest intervals of the Pleis tocene and Pliocene. Coupled with related modeling studies (e.g. Pollard and DeConto 2009), these data represent among the best opportunities to understand the potential collapse of the WAIS during past warm peast Interglacial (LIG) has become an important target for the question of WAIS stability (e.g. Siddall and Valdes 2011). Estimates of the same time, a number of model-data syntheses have concluded that the maximum contribution to sea level from Greenland was only several meters at most (see Colville et al. 2011 for a recent review) and the contributhen from thermal expansion was only in the gap of centimeters (Mckay et al. 2011). The gap between the eustatic sea-level rise and plausible Greenland and steric contributions ead to the unavoidable conclusion that the WAIS did indeed reduce dramatically for $G$ conditions. Further careful studies may well show more precisely by how much and under what oceanographic conditions this collapse occured, and whether collapses (Scherer et al. 2008; Hillenbrand et al. 2009). For human populations this issue does ot end with the question as to under what conditions will the WAIS begin to reduce dramatically. Two other questions arise at what rate will it reduce and how will the ice-volume be redistributed in the ocean?
Because of the availability of data, the ustatic sea level based on glacio-isostatic modeling of relative sea-level data for the LIG ndicate that sea levels approached around $8-9 m$ above modern (Kopp et al. 2009). At

Multiple studies of relative sea level during the LIG tentatively suggest rates of sea-level rise of the order of one meter per century resulting from ice sheet reduction beyond that which we have observed in the late Holocene (Rohling et al. 2008; Kopp et al. 2009; Thompson et al. 2011). Glacial isostatic adjustment (GIA) modeling of scenarios regarding the WAIS collapse indicate a 50\% variability in local sea-level rise resulting from the collapse of the WAIS (Mitrovica et al. 2009). GIA models have been constructed largely to explain GIA responses since the Last Glacial Maximum and therefore paleo data is crucial to understand if the WAIS will collapse in the coming century, the rate of sea-level rise and its global distribution. Given the complexity of ice sheet behavior it would be easy to become focused of the art deterministic models. Here we have argued for the careful, focused use of paleo data to understand the potential for the collapse of the WAIS in the next century and its implications for local populations.

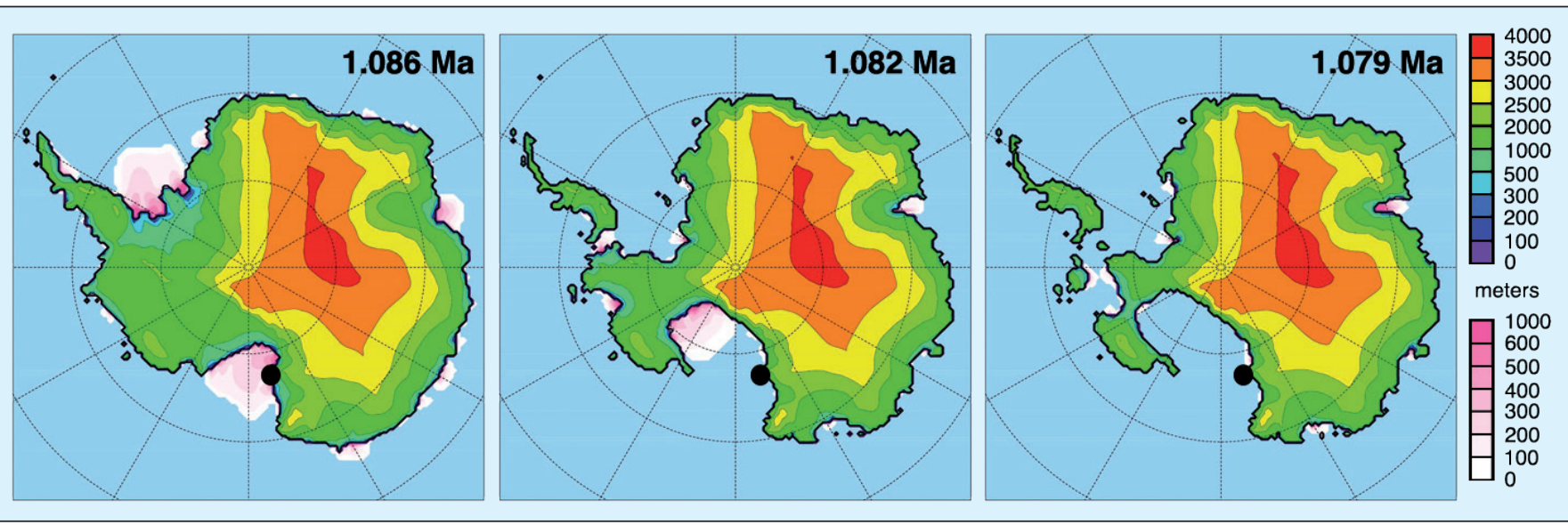

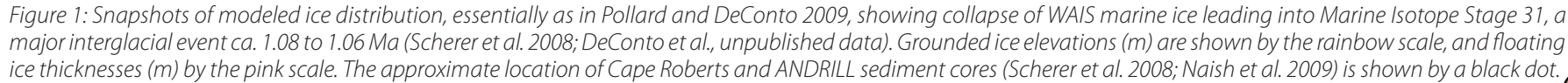

